\title{
Identifying factors predicting prolonged rehabilitation after simultaneous bilateral total knee arthroplasty: a retrospective observational study
}

Shu Takagawa ${ }^{1}$, Naomi Kobayashi ${ }^{1 *}$ D, Yohei Yukizawa ${ }^{1}$, Takayuki Oishi ${ }^{1}$, Masaki Tsuji ${ }^{1}$, Toshihiro Misumi ${ }^{2}$ and Yutaka Inaba ${ }^{3}$

\begin{abstract}
Background: Rehabilitation is an effective procedure for promoting functional recovery after simultaneous bilateral total knee arthroplasty (TKA); however, it has been cited as a significant economic burden of medical care. We hypothesized that preoperative factors, including age, sex, body mass index, living alone, the knee society function score (KSS), the American society of anesthesiologists (ASA) class, hemoglobin ( $\mathrm{Hb})$, albumin level, mean range of motion, and the Kellgren-Lawrence grade, would predict prolonged rehabilitation utilization.
\end{abstract}

Methods: In total, 191 patients undergoing simultaneous bilateral TKA in a single hospital were enrolled. The successful compliance group included patients who completed their rehabilitation program and could return to their residence within 3 weeks after surgery $(n=132)$, whereas the delayed group included the remaining patients $(n=59)$. Logistic regression analysis was performed using preoperative factors. A prediction scoring system was created using the regression coefficients from the logistic regression model.

Results: Logistic regression analysis revealed that age $(\beta=-0.0870 ; P<0.01)$ and $\mathrm{Hb}(\beta=0.34 ; P<0.05)$ were significantly associated with prolonged rehabilitation programs, whereas body mass index, living alone, KSS score, and ASA class were not significantly associated with successful completion of rehabilitation programs; however, these factors contributed to the prediction scoring formula, which was defined as follows:

Score $=10-(0.09 \times$ age $)-(0.09 \times$ body mass index $)-(0.56 \times$ living alone [alone $: 1$, others : 0$])+(0.03 \times \mathrm{KSS}$ stairs $)+(0.34 \times \mathrm{Hb})-(1.1 \times$ ASA class $)$.

The C-statistic for the scoring system was 0.748 (95\% confidence interval, 0.672-0.824). The positive and negative likelihood ratios were $2.228(95 \% \mathrm{Cl}, 1.256-3.950)$ and 0.386 (95\% Cl, 0.263-0.566), respectively. These results showed an increase of $15-20 \%$ and a decrease of $20-25 \%$ in the risk of prolonged rehabilitation. The optimal cutoff point for balancing sensitivity and specificity was 3.5 , with $66.6 \%$ sensitivity and $78.0 \%$ specificity.

(Continued on next page)

\footnotetext{
* Correspondence: naomik58@aol.com

'Department of Orthopaedic Surgery, Yokohama City University Medical

Center, 4-57 Urafune-cho, Minami-ku, Yokohama 232-0024, Japan

Full list of author information is available at the end of the article
}

(c) The Author(s). 2021 Open Access This article is licensed under a Creative Commons Attribution 4.0 International License, which permits use, sharing, adaptation, distribution and reproduction in any medium or format, as long as you give appropriate credit to the original author(s) and the source, provide a link to the Creative Commons licence, and indicate if changes were made. The images or other third party material in this article are included in the article's Creative Commons licence, unless indicated otherwise in a credit line to the material. If material is not included in the article's Creative Commons licence and your intended use is not permitted by statutory regulation or exceeds the permitted use, you will need to obtain permission directly from the copyright holder. To view a copy of this licence, visit http://creativecommons.org/licenses/by/4.0/ The Creative Commons Public Domain Dedication waiver (http://creativecommons.org/publicdomain/zero/1.0/) applies to the data made available in this article, unless otherwise stated in a credit line to the data. 
(Continued from previous page)

Conclusions: Older age and lower preoperative $\mathrm{Hb}$ were significantly associated with prolonged rehabilitation programs. We defined a new scoring formula using preoperative patient factors to predict prolonged rehabilitation utilization in patients undergoing simultaneous bilateral TKA.

Keywords: Total knee arthroplasty, Rehabilitation, Length of hospital stay, Hemoglobin, Delayed discharge

\section{Background}

Total knee arthroplasty (TKA) is a reliable treatment for damaged knee joints and provides excellent long-term results regarding pain relief and functional restoration in patients with osteoarthritis [1]. As knee osteoarthritis has historically been considered an asymmetric disease [2], contralateral knee osteoarthritis is common in patients with end-stage unilateral osteoarthritis who undergo TKA [3]; therefore, simultaneous bilateral TKA has been commonly performed [4]. Rehabilitation is an effective procedure for promoting functional recovery; however, the average annual rehabilitation cost per patient has increased recently [5].

A previous systematic review has reported on the risk factors for prolonged hospital stay [6], and a few studies have reported on the risk factors for increased duration of rehabilitation utilization [5, 7]. Therefore, predicting the duration of rehabilitation utilization among simultaneous bilateral TKA cases using a preoperative scoring system will be beneficial.

This study aimed to determine the risk factors predicting prolonged rehabilitation utilization after simultaneous bilateral TKA. In addition, we created a new scoring system to predict the necessary duration of physiotherapy after simultaneous bilateral TKA and evaluated the predictive ability of the model.

\section{Methods}

\section{Description of population}

This retrospective observational study was approved by the Institutional Review Board of Yokohama City University (B190700017), and informed consent was obtained from all patients. Inclusion criteria for the current study included patients whose knees were treated with consecutive, simultaneous bilateral TKA between January 2014 and December 2018 in a single hospital. In total, 212 patients met the inclusion criteria. We excluded 18 patients with rheumatoid arthritis, seven patients who could not participate in the rehabilitation program for reasons, such as postoperative thrombus embolism, and three patients with missing preoperative physical data. Finally, a total of 191 patients were enrolled in the study (Fig. 1). All patients were diagnosed with osteoarthritis.

\section{Surgical interventions and postoperative treatments}

Bilateral TKAs were performed sequentially by one team comprising five experienced orthopedic surgeons.
General anesthesia with peripheral nerve block was used for all patients, except for those who did not agree with or could not undergo peripheral nerve block due to complications. A lateral curved longitudinal skin incision and midvastus approach was employed. Intra- and extramedullary techniques were used for placement of femoral and tibial cutting guides, respectively. A modified gap-balancing technique was employed. A tourniquet was inflated before incision and deflated after cement hardening. The Scorpio NRG ${ }^{\bullet}$ posterior-stabilized prostheses (Stryker Orthopedics, Mahwah, NJ, USA) were used in all cases.

All patients, except those with anemia (hemoglobin $[\mathrm{Hb}]<11.0 \mathrm{~g} / \mathrm{dL}$ ), underwent two $400 \mathrm{~mL}$ autologous blood collections prior to surgery. Postoperative autologous blood transfusion of $800 \mathrm{~mL}$ was performed within 3 days after surgery, independent of $\mathrm{Hb}$ levels. In patients with $\mathrm{Hb}$ level $<11 \mathrm{~g} / \mathrm{dL}$, we could not collect autologous blood samples due to our hospital's autologous blood guidelines, and allogenic blood transfusion was performed in patients with $\mathrm{Hb}$ level $<7.5 \mathrm{~g} / \mathrm{dL}$ or those who were expected to progress to anemia because of postoperative bleeding.

Postoperative pain management comprised nonsteroidal anti-inflammatory drugs for internal use with an additional acetaminophen infusion when required. Rehabilitation was started on the day after surgery and continued until discharge. Full weight-bearing was allowed from the day after the surgery. Patients underwent a stepwise program to achieve the ability to use a wheelchair, followed by walking using a walker and Tcane, depending on compliance. In our facility, the rehabilitation goal was set within 3 weeks post-surgery following the clinical pathway. Generally, patients could not be discharged on time if stable independent walking with a T-cane and stepping up and down the stairs were not achieved within 3 weeks postoperatively. Patients were informed that a hospital transfer would be required if rehabilitation programs needed more than 3 weeks. Patients were discharged to their homes when they were able to walk using a T-cane and step up and down the stairs independently.

\section{Data collection}

Patient data, including age, sex, body mass index (BMI), living alone, Knee Society function score (KSS) [8], 


\section{Inclusion criteria}

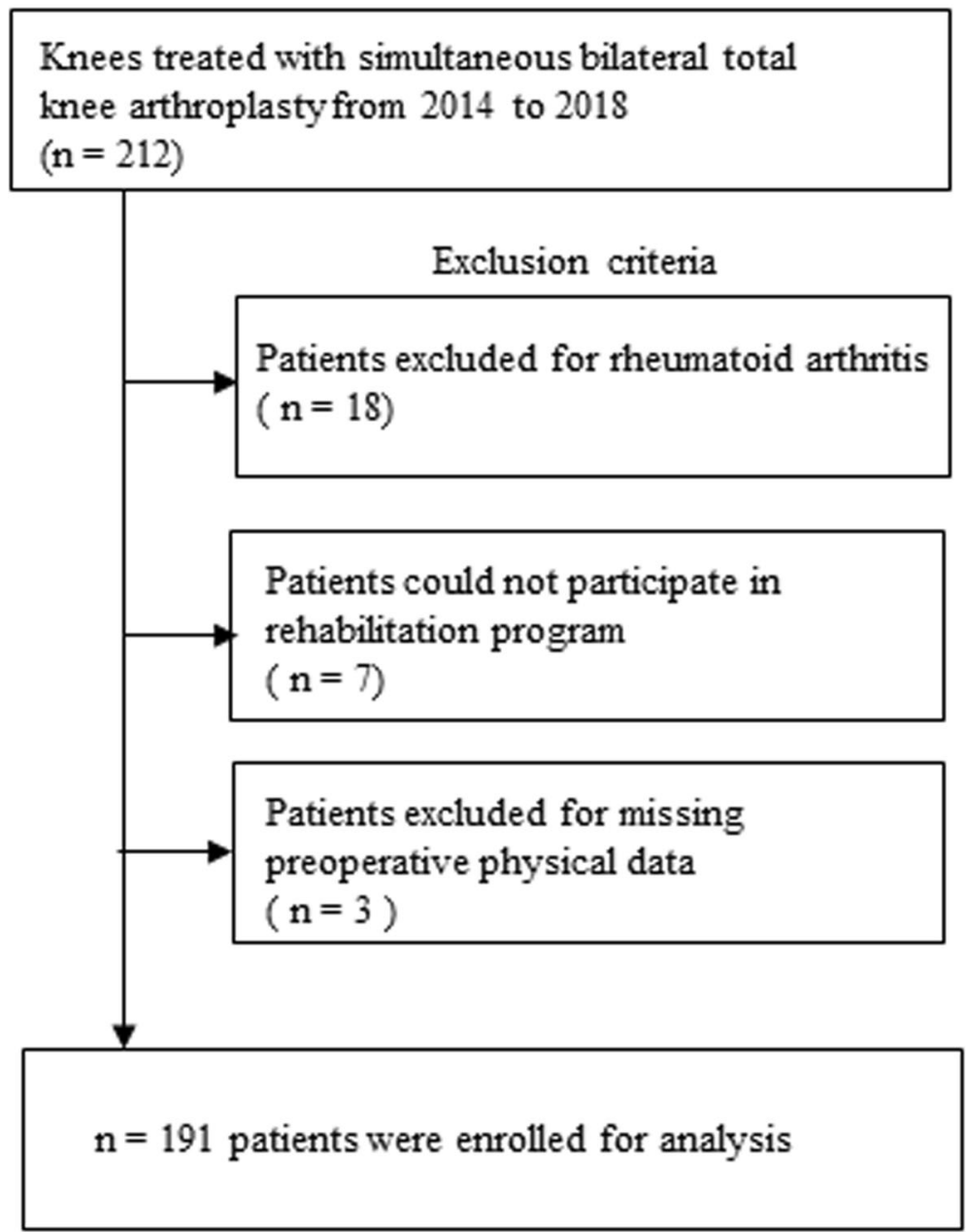

Fig. 1 Inclusion and exclusion criteria for the study participants

American Society of Anesthesiologists (ASA) class, preoperative Hb levels ( $\mathrm{g} / \mathrm{dL}$ ), serum albumin (Alb) level ( $\mathrm{g} /$ $\mathrm{dL}$, measured 8 weeks prior to surgery before autologous blood collection), mean range of motion (average of the two sides), and mean Kellgren-Lawrence classification ( $\mathrm{K}-\mathrm{L}$ grade, average of the two sides), were collected from the hospital's computer databases [9]. All parameters were obtained from the medical records at the time of preoperative outpatient examination and through patient interviews. The rehabilitation program utilization was calculated as the duration from the date of operation to the date of discharge from the hospital to the patient's home. Patients who were transferred to other hospitals due to delayed rehabilitation were analyzed separately as transferred cases. Patients who could return to their residence within 3 weeks after surgery were assigned to the compliance group $(n=132)$, whereas those who could not and transferred patients were assigned to the delayed group $(n=59)$.

\section{Statistical analysis}

Values are expressed as mean \pm standard deviation (SD). Compliance and delayed groups were defined as dependent variables. Age, sex, BMI, living alone, KSS, the ASA class, $\mathrm{Hb}$ levels, Alb levels, mean range of motion, and the $\mathrm{K}-\mathrm{L}$ grade were defined as predictor variables. Normally distributed data were analyzed using a non-paired t-test, whereas non-normally distributed data were analyzed using the Mann-Whitney $U$ test; the chisquare test was used for between-group comparisons of the preoperative parameters. Multivariate logistic regression analysis using a forward-backward stepwise selection method was performed to determine factors influencing successful compliance or prolonged rehabilitation programs. Standardized regression coefficients $(\beta)$ and associated $P$-values were determined to assess statistical significance. P-value $<0.05$ was considered statistically significant. According to the methods of Sullivan et al. [10] and Oba et al. [11], a prediction scoring 
formula was created using the multivariate logistic regression model results. Steyerberg et al. reported that stepwise selection with low alpha $(P<0.05)$ leads to a relatively poor model performance in cases with small samples [12]. Therefore, we created a prediction formula using factors resulting from the regression analysis $(P<0.20)$. Similarly, Zemek et al. selected variables using factors with $P<0.20$, which was considered to have some correlation with the results [13].

Scores were calculated by adding the results of multiplications between each independent factor and its coefficient $\beta$. To simplify the formula, up to three significant digits of the coefficient $\beta$ were used. Ten points were added to the formula to make the score positive. Cstatistics and likelihood ratio were used to assess the predictive ability of the model. Patients were stratified according to their score, and the observed probability of being in the compliance or delayed group was assessed. All statistical analyses were performed using the JMP 12.2 software (SAS Institute Inc., Cary, NC, USA).

\section{Results}

The distribution of the required rehabilitation duration is shown in Fig. 2. The range of duration of the compliance and delayed groups was $12-21$ and 22-29 days, respectively (mean 18.5 and 23.6 days, respectively). The mean duration of the delayed group excluded values from 13 transferred cases.

Patients in the delayed group were significantly older, used more walking aids, and had a higher ASA class as well as lower $\mathrm{Hb}$ and Alb levels than those in the compliance group. No significant differences between the groups were observed in sex ratio, BMI, the incidence of living alone, walking ability, stair-climbing ability, mean range of motion, and mean $\mathrm{K}-\mathrm{L}$ grade. The delayed group included 13 transferred cases. Patients' data are summarized in Table 1 . Table 2 shows the results of the logistic regression analysis, which indicated that age $(\beta=$ - 0.0870; $P=0.0059)$ and $\mathrm{Hb}(\beta=0.340 ; P=0.0370)$ were significantly associated with rehabilitation duration.

The prediction scoring formula was created as follows: score $=10-(0.09 \times$ age $)-(0.09 \times \mathrm{BMI})-(0.56 \times$ living alone [alone: 1 , others; 0$])+(0.03 \times \mathrm{KSS}$ stairs $)+(0.34 \times$ $\mathrm{Hb})-(1.1 \times$ ASA class $)$. Table 3 shows the formula and the observed probability of being in the compliance group for scores of $0-7$ points.

Figure 3 shows the receiver operating characteristic curve of the scoring system. The area under the curve (AUC) was 0.748 (95\% confidence interval [CI], 0.6720.824). The optimal cutoff point for balancing sensitivity and specificity was 3.5 , with $66.6 \%$ sensitivity and $78.0 \%$ specificity. Positive likelihood ratio was 2.228 (95\% CI,

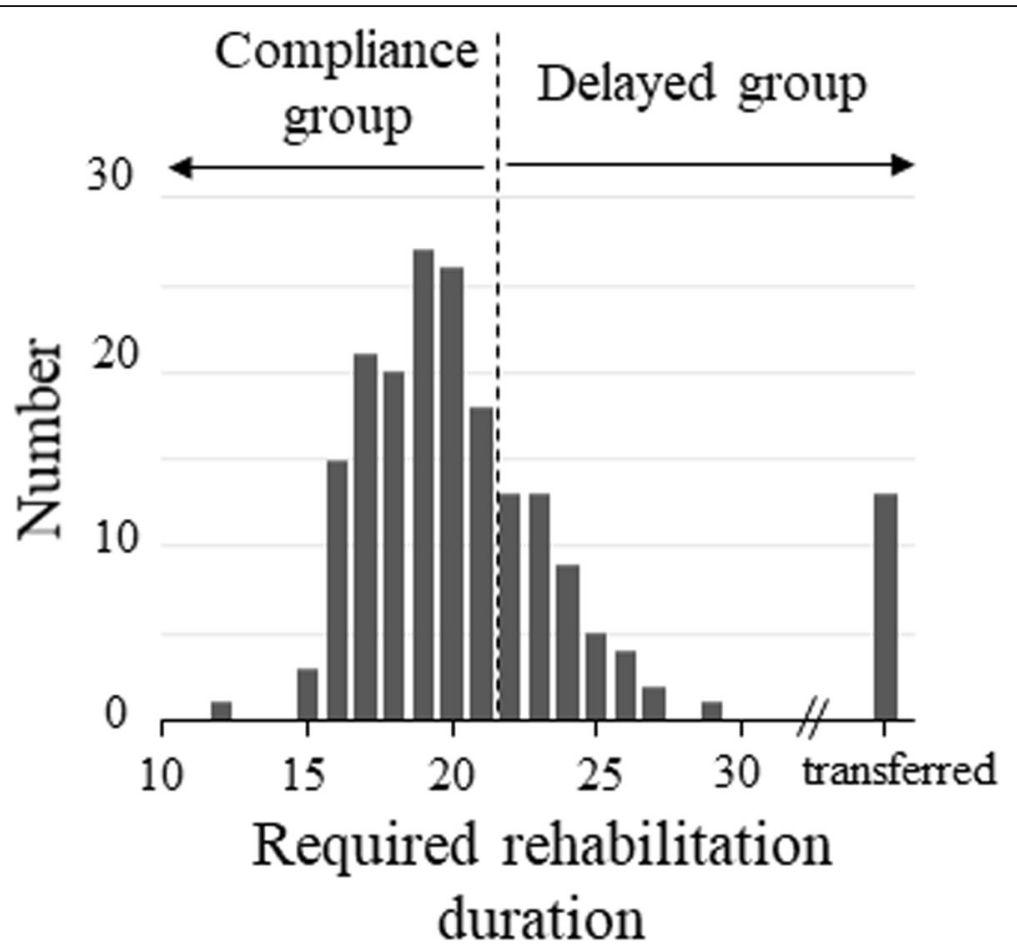

Fig. 2 Distribution of the required rehabilitation durations. Patients who required a rehabilitation duration of less than 21 days after surgery were assigned to the compliance group. Patients with a required rehabilitation duration of over 21 days and transferred cases were assigned to the delayed group 
Table 1 Summary of patient data

\begin{tabular}{|c|c|c|c|}
\hline All patients $(n=191)$ & Compliance group $(n=132)$ & Delayed group $(n=59)$ & $P$-value \\
\hline \multicolumn{4}{|l|}{ Age, years } \\
\hline$<60$ & 4 & 1 & \\
\hline $60-70$ & 26 & 6 & \\
\hline $70-80$ & 76 & 25 & \\
\hline $80-90$ & 26 & 27 & \\
\hline Average & 74.2 & 77.9 & $<0.001^{a}$ \\
\hline Female, \% & $83.3 \%$ & $88.1 \%$ & $0.393^{b}$ \\
\hline \multicolumn{4}{|l|}{ Body mass index, $\mathrm{kg} / \mathrm{m}^{2}$} \\
\hline$<20$ & 3 & 0 & \\
\hline $20-25$ & 38 & 20 & \\
\hline $25-30$ & 66 & 22 & \\
\hline $30-35$ & 22 & 13 & \\
\hline$>35$ & 3 & 4 & \\
\hline Average & 27.1 & 27.7 & $0.706^{c}$ \\
\hline Living alone, $\%$ & $15.9 \%$ & $27.1 \%$ & $0.077^{b}$ \\
\hline \multicolumn{4}{|l|}{ Knee Society score } \\
\hline Walking & 24.5 & 22.7 & $0.138^{c}$ \\
\hline Stairs & 27.1 & 23.2 & $0.061^{c}$ \\
\hline Walking aids used & 3.5 & 5.0 & $0.043^{c}$ \\
\hline Total & 48.1 & 41.6 & $0.057^{c}$ \\
\hline \multicolumn{4}{|l|}{ ASA class } \\
\hline । & 11 & 2 & \\
\hline$\|$ & 119 & 51 & \\
\hline III & 2 & 6 & \\
\hline Average & 1.93 & 2.07 & $0.009^{c}$ \\
\hline Hemoglobin, $\mathrm{g} / \mathrm{dL}$ & 13.1 & 12.6 & $0.014^{\mathrm{a}}$ \\
\hline Albumin, $\mathrm{g} / \mathrm{dL}$ & 4.4 & 4.3 & $0.018^{\mathrm{a}}$ \\
\hline \multicolumn{4}{|l|}{ Mean range of motion } \\
\hline Extension & 12.7 & 12.3 & $0.704^{c}$ \\
\hline Flexion & 113.4 & 114.5 & $0.964^{c}$ \\
\hline Mean K-L grade & 3.86 & 3.89 & $0.753^{c}$ \\
\hline Length of stay (days, excluding transferred cases) & 18.5 & 23.6 & $<0.001$ \\
\hline Transferred cases, number & 0 & 13 & \\
\hline
\end{tabular}

Values are presented as mean. $P$-values were obtained using the Mann-Whitney $U$ test or chi-square test

$n$ number, ASA American society of anesthesiologists, $K-L$ grade Kellgren-Lawrence classification

${ }^{a}$ Non-paired t-test

${ }^{b}$ chi-square test

'Mann-Whitney U test

1.256-3.950), and negative likelihood ratio was 0.386 (95\% CI, 0.263-0.566).

\section{Discussion}

The main point of clinical relevance in this study is the ability of preoperative factors to predict the likelihood of prolonged rehabilitation after simultaneous bilateral TKA. Based on our scoring formula, we predicted that less than half of the patients with a preoperative score of
$<3$ points would not complete the rehabilitation programs and would not be able to return to their residence.

The role of rehabilitation programs is considered essential as patients rapidly recover independent movement and transfer capacities during this period; thus, contributing to an early home discharge [7]. The mean length of stay (LOS) after TKA procedures has gradually decreased from 15 days to 5 days over the last few 
Table 2 Results of regression analysis

\begin{tabular}{|c|c|c|c|c|c|}
\hline \multirow[t]{2}{*}{ Variable } & \multirow[t]{2}{*}{ B } & \multirow{2}{*}{$\begin{array}{l}P \text { - } \\
\text { value }\end{array}$} & \multirow{2}{*}{$\begin{array}{l}\text { Odds } \\
\text { ratio }\end{array}$} & \multicolumn{2}{|l|}{$\mathrm{Cl}(95 \%)$} \\
\hline & & & & Lower & Uppe \\
\hline Age & -0.0870 & 0.00590 & 1.09 & 1.03 & 1.16 \\
\hline BMI & -0.0892 & 0.0565 & 1.09 & 0.998 & 1.20 \\
\hline Living alone & -0.563 & 0.165 & 0.579 & 0.257 & 1.27 \\
\hline Knee Society score: stairs & 0.0267 & 0.140 & 0.978 & 0.948231 & 1.01 \\
\hline Hemoglobin, $\mathrm{g} / \mathrm{dL}$ & 0.340 & 0.037 & 0.712 & 0.511493 & 0.971 \\
\hline ASA class & -1.13 & 0.0724 & 3.09 & 0.964960 & 12.0 \\
\hline
\end{tabular}

Cl confidence interval, $B M I$ body mass index, ASA American society of anesthesiologists

decades in Europe and the United States [6]; however, long-term hospitalization remains the norm in Japan [14]. In Japan, LOS after TKA included rehabilitation programs. The cutoff value was defined as 3 weeks in this study. The first reason for this is that the Japanese insurance system (diagnosis procedure combination [DPC]) defined 22 days post-hospital admission as the target to proceed with TKA. Thus, the Japanese insurance system enforces the LOS goal within 3 weeks postTKA as the acceptable clinical pathway. Second, in the early postoperative phase, the quadriceps strength is significantly lower than the preoperative levels [15], and it takes approximately 3 weeks to restore lower extremity function to pre-surgery levels [16].

Older age was associated with decreased complication functional scores (as represented by the KSS score) and increased postoperative complication rates [17]. Blood management has the most significant impact on LOS after TKA, and correction of preoperative anemia with iron and/or erythropoiesis-stimulating agents helps in decreasing transfusion risk [18]. Hb level is a factor that can be improved preoperatively. Therefore, it is important to inform the medical team that preoperative care of anemia using drugs and/or daily life guidance might reduce the required duration of rehabilitation postoperatively. In accordance with past findings, our study identified older age and low preoperative $\mathrm{Hb}$ levels as factors with the strongest association with delayed achievement of rehabilitation programs after simultaneous bilateral TKA. In contrast, BMI, living alone, KSS score, and ASA class were not significantly associated with the achievement of rehabilitation programs but contributed to the prediction scoring formula.

There are no obvious clinical indicators of the duration of rehabilitation required for functional recovery after simultaneous bilateral TKA. LOS following TKA decreases yearly [6], and it varied among patients who did not need a rehabilitation program after discharge. Physiotherapy exercises following TKA have both shortand long-term benefits for patients [19]. Because of limited medical resources, preoperative assessment of each patient is required to estimate the rehabilitation period needed for them to become independent and capable of activities of daily living (ADL); such assessment may improve the efficiency of rehabilitation programs. Therefore, the identification of individual predictive factors will benefit clinical decision-making. Quadriceps muscle strength is an important determinant of physical

Table 3 Scoring formula and the observed probability of required rehabilitation duration

\begin{tabular}{|c|c|c|c|c|c|c|}
\hline \multicolumn{2}{|l|}{ Scoring formula } & \multicolumn{5}{|c|}{ Outcomes } \\
\hline Factors & Points & $\begin{array}{l}\text { Total } \\
\text { score }\end{array}$ & $n$ & $\begin{array}{l}\text { Compliance } \\
\text { group }\end{array}$ & $\begin{array}{l}\text { Delayed } \\
\text { group }\end{array}$ & $\begin{array}{l}\text { Observed probability of required rehabilitation duration } \\
\text { conformance, } \%\end{array}$ \\
\hline & +10 & $0-1$ & 1 & 0 & 1 & $0.0 \%$ \\
\hline Age, (years) & $\begin{array}{l}\times \\
-0.09\end{array}$ & $1-2$ & 9 & 2 & 7 & $22.2 \%$ \\
\hline BMI & $\begin{array}{l}\times \\
-0.09\end{array}$ & $2-3$ & 40 & 20 & 20 & $50.0 \%$ \\
\hline Living alone & $\begin{array}{l}\times \\
-0.56\end{array}$ & $3-4$ & 74 & 52 & 22 & $70.3 \%$ \\
\hline KSS: stairs & $\times 0.03$ & $4-5$ & 47 & 41 & 6 & $87.2 \%$ \\
\hline $\begin{array}{l}\text { Hemoglobin, g/ } \\
\text { dL }\end{array}$ & $\times 0.34$ & $5-6$ & 13 & 11 & 2 & $84.6 \%$ \\
\hline ASA class & $x-1.1$ & $6-7$ & 7 & 6 & 1 & $85.7 \%$ \\
\hline
\end{tabular}

$n$ number, KSS knee society score, BMI body mass index 


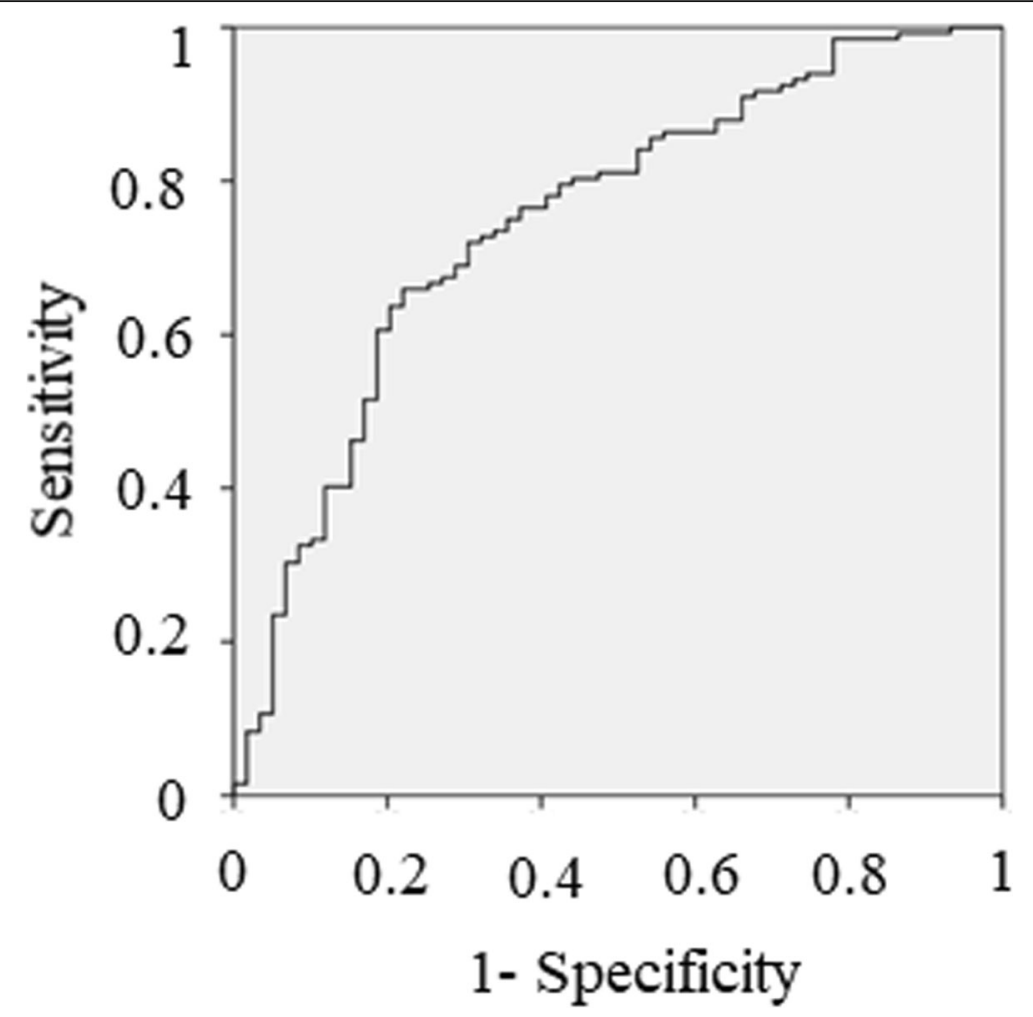

Fig. 3 Prediction of compliance with the target. The figure depicts the prediction of compliance with a target of less than 3 weeks duration of required rehabilitation

function after TKA [6]. Therefore, lower limb strengthening may be effective in achieving independence to complete ADL earlier. Recently, Ueyama et al. [20] reported that nutritional supplements rich in essential amino acids prevent femoris muscle atrophy and postoperatively accelerate the time taken to recover ADL to that of baseline level. If the preoperative prediction system can identify patients with delayed recovery of ADL, it may be possible to selectively and efficiently perform interventions, such as nutritional supplementation.

Return to residence after surgery is associated with multiple factors, including the patient's social background, which may influence the achievement of rehabilitation programs. Our study demonstrated a simple method to calculate scores at the time of scheduling outpatients for surgery. The prediction scoring system may facilitate social services when early discharge is likely, and adjustment when transfer to a rehabilitation hospital is likely. For cases with lower scores under the 3.5-point cutoff value, it is especially important to treat anemia and inform patients and their families that it might take longer to perform ADL independently.

The purpose of this investigation was to derive a prediction model to identify patients at risk for prolonged rehabilitation following simultaneous bilateral TKA. Further investigation is required to validate the model and more data must be added to refine the model. We restricted this investigation to patients undergoing bilateral TKA within the Japanese healthcare system. While postoperative care varies among countries and regions, our main findings in which age and low $\mathrm{Hb}$ predict longer recovery are likely generalizable beyond these restrictions. We chose to construct the prediction formula using factors with $P<0.20$. In cases wherein only age and $\mathrm{Hb}$ values were used $(P<0.05)$, the AUC was 0.697 (95\% CI, 0.603-0.786). Hence, we included factors with $\mathrm{P}<0.20$ for the construction of the prediction formula to avoid a relatively poor model performance, which may result from using only factors with $P<0.05$. In addition, we recognize that there may be other factors that contribute to the prediction of postoperative outcomes. Preoperative pain assessment was not included in this study. Preoperative central sensitization was recently identified as a significant risk factor for postoperative persistent pain and dysfunction [21], leading to prolonged duration of rehabilitation. Thus, preoperative central sensitization might be a significant factor influencing the scoring formula and is suggested for inclusion in future investigations.

Several limitations of our study should be addressed. First, the sample size in this study was relatively small. Therefore, further studies with a larger sample size are 
required to validate the reliability of our scoring system. Second, we excluded patients with rheumatoid arthritis and postoperative complications. Patients with rheumatoid arthritis tend to have a longer duration of hospitalization and discharge to rehabilitation facilities than patients with osteoarthritis, independent of adverse events [22]. Third, the study population predominantly comprised Japanese, and the results may not be generalizable to other demographic groups. In other countries, LOS following TKA is much shorter than that in Japan. Furthermore, LOS was strongly influenced by the patient's expectation of when they could be discharged home based on preoperative education programs [23]. Hence, additional investigations are needed to validate the scoring system in other countries and different situations. Fourth, the a positive likelihood ratio between 2 and 3 indicated an increase in probability by 15-20\%, and a negative likelihood ratio between 0.3 and 0.4 indicated a decrease in probability by $20-25 \%$ [24]. These results did not show a significant increase and/or decrease in the likelihood of predicting increased rehabilitation duration. Fifth, age was the most influential factor in this study; therefore, other risk factors might not be fully identified. To create a more clinically useful predictive formula, it might be useful to perform analysis in a certain range of older age group. Therefore, to construct a more accurate prediction formula, it is necessary to collect and examine a larger number of cases and additional information before applying these predictors in actual clinical practice.

\section{Conclusion}

Older age and lower preoperative $\mathrm{Hb}$ were significantly associated with prolonged rehabilitation programs. We defined a new scoring formula using preoperative patient factors to predict prolonged rehabilitation utilization in patients undergoing simultaneous bilateral TKA. Further studies are warranted to confirm the value of this scoring system and improve its accuracy.

\section{Abbreviations \\ TKA: Total knee arthroplasty; KSS: Knee society function score; ASA: American society of anesthesiologist; BMl: Body mass index; Hb: Hemoglobin; Alb: Albumin; LOS: Length of stay; DPC: Diagnosis procedure combination; K-L: Kellgren-Lawrence classification; ADL: Activities of daily living}

\section{Acknowledgments}

We thank all the patients involved in the study.

\section{Authors' contributions}

ST, NK, and YI designed the study; ST and MT analyzed the data; ST and NK wrote the manuscript; $Y Y$ and TO interpretation of data, and YY, MT, and TO supervised the study. All authors read and approved the final manuscript.

\section{Funding}

There were no sources of funding for this study.

\section{Availability of data and materials}

The datasets during and/or analyzed during the current study available from the corresponding author on reasonable request.

\section{Declarations}

\section{Ethics approval and consent to participate}

Ethical approval for the study was obtained from the institutional review board of Yokohama City University (IRB No. B190700017). Informed and written consent was obtained from all patients.

\section{Consent for publication}

Not applicable.

\section{Competing interests}

The authors declare that they have no competing interests.

\section{Author details}

${ }^{1}$ Department of Orthopaedic Surgery, Yokohama City University Medical Center, 4-57 Urafune-cho, Minami-ku, Yokohama 232-0024, Japan. ${ }^{2}$ Department of Biostatistics, Yokohama City University School of Medicine, 3-9, Fukuura, Kanazawa-ku, Yokohama 236-0004, Japan. ${ }^{3}$ Department of Orthopaedic Surgery, Yokohama City University Graduate School of Medicine, 3-9, Fukuura, Kanazawa-ku, Yokohama 236-0004, Japan.

Received: 2 October 2020 Accepted: 31 March 2021

Published online: 20 April 2021

\section{References}

1. Kobayashi S, Niki Y, Harato K, Nagura T, Nakamura M, Matsumoto M. Rheumatoid arthritis patients achieve better satisfaction but lower functional activities as compared to osteoarthritis patients after total knee arthroplasty. J Arthroplast. 2019;34(3):478-82. https://doi.org/10.1016/j.arth.2 018.11.003.

2. Metcalfe AJ, Andersson MLE, Goodfellow R, Thorstensson C. Is knee osteoarthritis a symmetrical disease? Analysis of a 12 year prospective. BMC Musculoskelet Disord. 2012;13(1):153. https://doi.org/10.1186/1471-2474-13-1 53.

3. Gunther KP, Stürmer T, Sauerland S, Zeissig I, Sun Y, Kessler S. Prevalence of generalised osteoarthritis in patients with advanced hip and knee. Ann Rheum Dis. 1998:57(12):717-23. https://doi.org/10.1136/ard.57.12.717.

4. Lindberg-Larsen M, Pitter FT, Husted H, Kehlet H, Jørgensen CC, Lundbeck Foundation Centre for Fast-Track Hip and Knee Replacement Collaborative Group. Simultaneous vs staged bilateral total knee arthroplasty: a propensity-matched case-control study from nine fast-track centres. Arch Orthop Trauma Surg. 2019;139(5):709-16. https://doi.org/10.1007/s00402-01 9-03157-z.

5. Bettger PJ, Green CL, Holmes DN, Chokshi A, Mather RC 3rd, Hoch BT, et al. Effects of virtual exercise rehabilitation in-home therapy compared with traditional care after total knee arthroplasty: VERITAS, a randomized controlled trial. J Bone Joint Surg Am. 2020;102(2):101-9. https://doi.org/1 0.2106/JBJS.19.00695.

6. Shah A, Memon M, Kay J, Wood TJ, Tushinski DM, Khanna V, et al. Preoperative patient factors affecting length of stay following total knee arthroplasty: A systematic review and meta-analysis. J Arthroplast. 2019;34: 2124-65 e1

7. Dauty M, Smitt X, Menu P, Dubois C. Which factors affect the duration of inpatient rehabilitation after total knee arthroplasty in the absence of complications? Ann Phys Rehabil Med. 2009;52(3):234-45. https://doi.org/1 0.1016/j.rehab.2009.01.001

8. Insall JN, Dorr LD, Scott RD, Scott WN. Rationale of the knee society clinical rating system. Clin Orthop Relat Res. 1989;248:13-4.

9. Kellgren JH, Lawrence JS. Radiological assessment of osteo-arthrosis. Ann Rheum Dis. 1957;16(4):494-502. https://doi.org/10.1136/ard.16.4.494

10. Sullivan LM, Massaro JM, D'Agostino RB Sr. Presentation of multivariate data for clinical use: the Framingham study risk score functions. Stat Med. 2004; 23(10):1631-60. https://doi.org/10.1002/sim.1742.

11. Oba T, Makita H, Inaba Y, Yamana H, Saito T. New scoring system at admission to predict walking ability at discharge for patients with hip fracture. Orthop Traumatol Surg Res. 2018;104(8):1189-92. https://doi.org/1 0.1016/j.otsr.2018.07.024. 
12. Steyerberg EW, Eijkemans MJ, Harrell FE Jr, Habbema JD. Prognostic modelling with logistic regression analysis: a comparison of selection and estimation methods in small data sets. Stat Med. 2000;19(8):1059-79. https://doi.org/10.1002/(SICI)1097-0258(20000430)19:8<1059:AID-SIM412>3. 0.CO;2-0.

13. Zemek R, Barrowman N, Freedman SB, Gravel J, Gagnon I, McGahern C, et al. Clinical risk score for persistent postconcussion symptoms among children with acute concussion in the ED. JAMA. 2016;315(10):1014-25. https://doi.org/10.1001/jama.2016.1203.

14. Ishii Y, Noguchi H, Takeda M, Sato J, Suzuki T. Length of hospital stay with patient-dependent determination in bilateral. Eur J Orthop Surg Traumatol. 2014;24(6):961-5. https://doi.org/10.1007/s00590-013-1262-6.

15. Bade MJ, Stevens-Lapsley JE. Restoration of physical function in patients following total knee arthroplasty: an update on rehabilitation practices. Curr Opin Rheumatol. 2012;24(2):208-14. https://doi.org/10.1097/BOR.0b013e32 834ff26d.

16. Kennedy DM, Stratford PW, Hanna SE, Wessel J, Gollish JD. Modeling early recovery of physical function following hip and knee arthroplasty. BMC Musculoskelet Disord. 2006;7(1):100. https://doi.org/10.1186/1471-2474-7-1 00 .

17. Fang M, Noiseux N, Linson E, Cram P. The effect of advancing age on total joint replacement outcomes. Geriatr Orthop Surg Rehabil. 2015;6(3):173-9. https://doi.org/10.1177/2151458515583515.

18. Monsef JB, Della Valle AG, Mayman DJ, Marx RG, Ranawat AS, Boettner F. The impact of blood management on length of stay after primary total knee. Open Orthop J. 2014;8(1):108-13. https://doi.org/10.2174/18743250014 08010108.

19. Artz N, Karen TE, Lowe CM, Sackley C, Jepson P, Beswick AD. Effectiveness of physiotherapy exercise following total knee replacement: systematic review and meta-analysis. BMC Musculoskelet Disord. 2015;16(1):15. https:// doi.org/10.1186/s12891-015-0469-6.

20. Ueyama H, Kanemoto N, Minoda Y, Taniguchi Y, Nakamura H. 2020 Chitranjan S. Ranawat award: perioperative essential amino acid supplementation suppresses rectus femoris muscle atrophy and accelerates early functional recovery following total knee arthroplasty. Bone Joint J. 2020;102-B(6_Supple_A):10-8. https://doi.org/10.1302/0301-620X.102B6.BJJ-2 019-1370.R1.

21. Koh IJ, Kang BM, Kim MS, Choi KY, Sohn S, In Y. How does preoperative central sensitization affect quality of life following total knee arthroplasty? J Arthroplast. 2020;35(8):2044-9. https://doi.org/10.1016/j.arth.2020.04.004.

22. Stundner O, Danninger T, Chiu Y, Sun X, Goodman SM, Russell LA. Rheumatoid arthritis vs. osteoarthritis in patients receiving total knee arthroplasty: perioperative outcomes. J Arthroplast. 2014;29(2):308-13. https://doi.org/10.1016/j.arth.2013.05.008.

23. Yoon RS, Nellans KW, Geller JA, Kim AD, Jacobs MR, Macaulay W. Patient education before hip or knee arthroplasty lowers length of stay. J Arthroplast. 2010;25(4):547-51. https://doi.org/10.1016/j.arth.2009.03.012.

24. McGee S. Simplifying likelihood ratios. J Gen Intern Med. 2002;17(8):646-9. https://doi.org/10.1046/j.1525-1497.2002.10750.x.

\section{Publisher's Note}

Springer Nature remains neutral with regard to jurisdictional claims in published maps and institutional affiliations.

Ready to submit your research? Choose BMC and benefit from:

- fast, convenient online submission

- thorough peer review by experienced researchers in your field

- rapid publication on acceptance

- support for research data, including large and complex data types

- gold Open Access which fosters wider collaboration and increased citations

- maximum visibility for your research: over $100 \mathrm{M}$ website views per year

At BMC, research is always in progress.

Learn more biomedcentral.com/submissions 